\title{
Is tenofovir and entecavir combination therapy still the optimal treatment for chronic hepatitis B patients with prior suboptimal response?
}

\author{
Byoung Kuk Jang \\ Department of Internal Medicine, Keimyung University School of Medicine, Daegu, Korea
}

Keywords: Chronic hepatitis B; Entecavir; Suboptimal response; Tenofovir

See Article on Page 352

It is well-known that consistently high hepatitis B virus (HBV) DNA levels increase the risk of fibrosis progression and hepatocellular carcinoma (HCC) development in patients with chronic hepatitis $B(C H B) .^{1,2}$ Therefore, the primary goal of CHB treatment is complete suppression of HBV DNA by antiviral treatment. ${ }^{3}$ Before the introduction of nucleos(t)ide analogues (NAs) with a high genetic barrier, such as entecavir (ETV) and tenofovir disoproxil fumarate (TDF), long-term treatment of NAs with a low genetic barrier, such as lamivudine (LAM), adefovir dipivoxil (ADV) and telbivudine (LdT), led to drug resistance in many CHB patients. ${ }^{3.5}$ Until the introduction of ETV or TDF, the standard treatment was to add ADV to LAM or LdT for the treatment of CHB patients with LAM or LdT resistance. ${ }^{6}$ However, CHB patients receiving LAM or LdT/ADV combination therapy often show a suboptimal response.? In patients with this suboptimal response, it is known that the risk of developing resistance to various NAs increases, as well as the risk of developing end-stage liver disease and $\mathrm{HCC}^{8}$ Therefore, the current guidelines recommended that HBV DNA maintain serum HBV DNA level below the detection limit of real-time polymerase chain reaction as the primary treatment goal. ${ }^{3,5,9}$ In the past, a combination of ETV-based regimens had been attempted to treat the CHB patients who had suboptimal response to LAM or LdT/ADV combination therapy. ${ }^{10,11}$ However, since the introduction of TDF with strong antiviral efficacy in the treatment of CHB, TDF monotherapy or TDF+other NAs regimens have been attempted to treat patients with various drug resistance. ${ }^{12-16}$ Berg et al. ${ }^{12}$ conducted a prospective randomized controlled trial to compare the antiviral effects of TDF monotherapy and TDF+emtricitabine (FTC) combination therapy in patients with suboptimal responses to ADV. According to the results of their study, complete virologic response (CVR) of TDF monotherapy and TDF+FTC combination therapy groups was $81 \%$ and $81 \%$, respectively, at 48 weeks; and there was no difference between the two groups. ${ }^{12}$ In a retrospective study of $\mathrm{CHB}$ patients with suboptimal response to ADV with or without NAs in LAM-resistant CHB, Cho et al..$^{13}$ showed that the CVR of TDF monotherapy group and TDF with NA combination group at 48 weeks was $81.8 \%$ and $85.9 \%$, respectively; and

\section{Abbreviations:}

ADV, adefovir dipivoxil; CHB, chronic hepatitis B; CVR, complete virologic response; ETV, entecavir; FTC, emtricitabine; HBV, hepatitis $B$ virus; $H C C$, hepatocellular carcinoma; LAM, lamivudine; LdT, telbivudine; NAs, nucleos(t)ide analogues; TAF, tenofovir alafenamide; TDF, tenofovir disoproxil fumarate

\section{Corresponding author : Byoung Kuk Jang}

Department of Internal Medicine, Keimyung University School of Medicine, 1035 Dalgubeol-daero, Dalseo-gu, Daegu 42601, Korea

Tel: +82-53-258-7720, Fax: +82-53-258-4343

E-mail: jangha106@dsmc.or.kr

https://orcid.org/0000-0002-8950-0866 
there was also no significant difference between the two groups $(P=0.075)$. In a small randomized controlled trial, Lee et al. ${ }^{14}$ compared the antiviral efficacy between switching to TDF+NAs therapy and continuing current ADV+NA therapy in patients with suboptimal response to ADV-based therapy. The results of their study showed that TDF+NAs therapy was significantly higher in CVR compared to continued ADV+NA ( $87.5 \%$ vs. $37.5 \%$ at 48 weeks, $P=0.002) .^{14}$ In addition, TDF showed good effects on CHB patients with ETV, ADV resistance, and multidrug resistance, as well as LAM resistance. ${ }^{15,16}$ Lim et al. ${ }^{15}$ compared the effects of TDF monotherapy versus TDF and ETV combination therapy in patients with ETV-resistant CHB with multiple drug failure in a randomized controlled trial, and the CVR of TDF and TDF+ETV groups was $71 \%$ and $73 \%$, respectively, at 48 weeks. There was no difference between the two groups $(P=0.99){ }^{15}$ In a study comparing the effects of TDF monotherapy versus TDF and ETV combination therapy in ADV-resistant CHB patients with multiple drug failure, the CVR at 48 weeks was $62 \%$ and $63.5 \%$ for TDF and TDF/ETV groups, respectively; and there was also no significant difference between the two groups $(P=0.88){ }^{16}$ Moreover, the results of several different studies showed no difference in CVR between TDF monotherapy and TDF+ETV combination therapy, the combination regimen of the most potent NAs to date, in CHB patients who are resistant to various NAs (Table 1).

Woo et al. conducted a prospective randomized controlled study to compare the effectiveness and efficacy between TDF+ETV therapy and LAM/LdT+ADV maintenance therapy for LAM-resistant patients who had suboptimal responses to
LAM+ADV combination therapy. As predicted from the results of many previous clinical studies, the results of this study showed that TDF+ETV group had a significantly higher CVR at 48 weeks compared to LAM/LdT+ADV maintenance therapy group (93.33\% vs. $6.52 \%, P<0.001)$. The clinical significance of this study was to confirm the expected results based on the results of previous retrospective studies through prospective trials. However, based on the results of several studies, including the studies conducted by Lim et al., ${ }^{15,16}$ TDF monotherapy alone was expected to have a sufficient effect even in patients with suboptimal responses to LAM+ADV. Therefore, this study had a significant limitation of not comparing the effect of TDF monotherapy group to that of TDF+ETV group. In real clinical practice, most patients with LAM+ADV suboptimal responses have already been treated with either TDF monotherapy or TDF+NAs combination therapy. Therefore, the results of this study may be considered a little late to have practical significance in clinical practice. Recently, patients who participated in the two aforementioned studies conducted by Lim et al..$^{17}$ reported the results of treatment for 244 weeks after switching from TDF+ETV to TDF monotherapy at 48 weeks. The CVR in ETV and ADV resistance groups increased to $84.4 \%$ and $73.5 \%$, respectively, at 240 weeks; and there was no significant difference between the two groups $(P=0.07)$. However, eGFR and bone mineral density were significantly decreased at the 240 week time point compared to the baseline $(P<0.001)$, reflecting the concern about the safety of long-term use of TDF. ${ }^{17}$ Due to these adverse effects of TDF, tenofovir alafenamide (TAF) has been recommended recently, especially in patients who are at risk

Table 1. Summary of anti-viral efficacy results of tenofovir-based therapy in patients with suboptimal response or resistance to NAs

\begin{tabular}{|c|c|c|c|c|c|}
\hline Study & Study design & Study population & Intervention & $\begin{array}{l}\text { Primary efficacy end } \\
\text { point }\end{array}$ & $\begin{array}{l}\text { Virologic } \\
\text { response }\end{array}$ \\
\hline Berg et al..$^{12}(2010)$ & Prospective & Suboptimal response to ADV & $\begin{array}{l}\text { TDF }(n=53) \text { vs. } \\
\text { TDF/FTC }(n=52)\end{array}$ & $\begin{array}{l}\text { HBV DNA level }<400 \\
\text { copies/mL at } 48 \text { weeks }\end{array}$ & $\begin{array}{l}81 \% \text { vs. } 81 \% \\
(P=N S)\end{array}$ \\
\hline Cho et al. ${ }^{13}$ (2015) & Retrospective & $\begin{array}{l}\text { Suboptimal response to ADV } \\
\text { with or without NAs in } \\
\text { LAM-resistant }\end{array}$ & $\begin{array}{l}\text { TDF }(n=18) \text { vs. } \\
\text { TDF/NA }(n=107)\end{array}$ & $\begin{array}{l}\text { HBV DNA level }<20 \mathrm{IU} / \mathrm{mL} \\
\text { at } 48 \text { weeks }\end{array}$ & $\begin{array}{l}81.8 \% \text { vs. } 85.9 \% \\
\quad(P=0.750)\end{array}$ \\
\hline Lee et al. ${ }^{14}(2016)$ & Prospective & $\begin{array}{l}\text { Partial responses to ADV+NA } \\
\text { therapy for NA resistance }\end{array}$ & $\begin{array}{l}\text { TDF/NA }(n=16) \text { vs. } \\
\text { continued ADV/NA } \\
(n=16)\end{array}$ & $\begin{array}{l}\text { HBV DNA level }<60 \mathrm{IU} / \mathrm{mL} \\
\text { at } 48 \text { weeks }\end{array}$ & $\begin{array}{l}81.3 \% \text { vs. } 56.3 \% \\
\quad(P<0.001)\end{array}$ \\
\hline Lim et al. ${ }^{15}$ (2016) & Prospective & ETV-resistant & $\begin{array}{l}\text { TDF }(n=45) \text { vs. } \\
\text { TDF/ETV }(n=45)\end{array}$ & $\begin{array}{l}\text { HBV DNA level }<15 \mathrm{IU} / \mathrm{mL} \\
\text { at } 48 \text { weeks }\end{array}$ & $\begin{array}{l}71 \% \text { vs. } 73 \% \\
(P=0.99)\end{array}$ \\
\hline Lim et al. ${ }^{16}(2016)$ & Prospective & ADV-resistant & $\begin{array}{l}\text { TDF }(n=50) \text { vs. } \\
\text { TDF/ETV }(n=52)\end{array}$ & $\begin{array}{l}\text { HBV DNA level }<15 \mathrm{IU} / \mathrm{mL} \\
\text { at } 48 \text { weeks }\end{array}$ & $\begin{array}{l}62 \% \text { vs. } 63.5 \% \\
\quad(P=0.88)\end{array}$ \\
\hline
\end{tabular}

NA, nucleos(t)ide analogue; ADV, adefovir dipivoxil; TDF, tenofovir disoproxil fumarate; FTC, emtricitabine; HBV, hepatitis B virus; NS, not significant; LAM, lamivudine; ETV, entecavir. 
of developing renal or bone disease. ${ }^{3,5}$ Therefore, in the future, clinical studies are needed to verify the effectiveness of TAFbased regimens in patients with CHB who are resistant or suboptimal to various NAs.

\section{Conflicts of Interest}

The author has no conflicts of interests to disclose.

\section{REFERENCES}

1. Chen CJ, Yang HI, Su J, Jen CL, You SL, Lu SN, et al. Risk of hepatocellular carcinoma across a biological gradient of serum hepatitis $B$ virus DNA level. JAMA 2006;295:65-73.

2. Iloeje UH, Yang HI, Su J, Jen CL, You SL, Chen CJ, et al. Predicting cirrhosis risk based on the level of circulating hepatitis $B$ viral load. Gastroenterology 2006;130:678-686.

3. European Association For The Study of The Liver. EASL clinical practice guidelines: management of chronic hepatitis B. J Hepatol 2009;50:227-242.

4. Lok AS, Lai CL, Leung N, Yao GB, Cui ZY, Schiff ER, et al. Long-term safety of lamivudine treatment in patients with chronic hepatitis $B$. Gastroenterology 2003;125:1714-1722.

5. Korean Association for the Study of the Liver (KASL). KASL clinical practice guidelines for management of chronic hepatitis B. Clin Mol Hepatol 2019;25:93-159.

6. Rapti I, Dimou E, Mitsoula P, Hadziyannis SJ. Adding-on versus switching-to adefovir therapy in lamivudine-resistant HBeAg-negative chronic hepatitis B. Hepatology 2007;45:307-313.

7. Lee JM, Park JY, Kim DY, Nguyen T, Hong SP, Kim SO, et al. Longterm adefovir dipivoxil monotherapy for up to 5 years in lamivudineresistant chronic hepatitis B. Antivir Ther 2010;15:235-241.

8. Lampertico P. Partial virological response to nucleos(t)ide analogues in naïve patients with chronic hepatitis $B$ : from guidelines to field practice. J Hepatol 2009;50:644-647.

9. Terrault NA, Lok ASF, McMahon BJ, Chang KM, Hwang JP, Jonas
$M M$, et al. Update on prevention, diagnosis, and treatment of chronic hepatitis B: AASLD 2018 hepatitis B guidance. Hepatology 2018;67:1560-1599.

10. Chang TT, Gish RG, Hadziyannis SJ, Cianciara J, Rizzetto M, Schiff $E R$, et al. A dose-ranging study of the efficacy and tolerability of entecavir in Lamivudine-refractory chronic hepatitis B patients. Gastroenterology 2005;129:1198-1209.

11. Sherman M, Yurdaydin C, Simsek H, Silva M, Liaw YF, Rustgi VK, et al. Entecavir therapy for lamivudine-refractory chronic hepatitis $B$ : improved virologic, biochemical, and serology outcomes through 96 weeks. Hepatology 2008;48:99-108.

12. Berg T, Marcellin P, Zoulim F, Moller B, Trinh H, Chan S, et al. Tenofovir is effective alone or with emtricitabine in adefovir-treated patients with chronic-hepatitis B virus infection. Gastroenterology 2010;139:1207-1217.

13. Cho HJ, Kim SS, Shin SJ, Yoo BM, Cho SW, Cheong JY. Tenofovirbased rescue therapy in chronic hepatitis $B$ patients with suboptimal responses to adefovir with prior lamivudine resistance. J Med Virol 2015;87:1532-1538.

14. Lee HW, Park JY, Kim BK, Kim MY, Lee JI, Kim YS, et al. Efficacy of switching from adefovir to tenofovir in chronic hepatitis B patients who exhibit suboptimal responses to adefovir-based combination rescue therapy due to resistance to nucleoside analogues (SATIS study). Clin Mol Hepatol 2016;22:443-449.

15. Lim YS, Byun KS, Yoo BC, Kwon SY, Kim YJ, An J, et al. Tenofovir monotherapy versus tenofovir and entecavir combination therapy in patients with entecavir-resistant chronic hepatitis B with multiple drug failure: results of a randomised trial. Gut 2016;65:852-860.

16. Lim YS, Yoo BC, Byun KS, Kwon SY, Kim YJ, An J, et al. Tenofovir monotherapy versus tenofovir and entecavir combination therapy in adefovir-resistant chronic hepatitis B patients with multiple drug failure: results of a randomised trial. Gut 2016;65:1045-1051.

17. Lim YS, Gwak GY, Choi J, Lee YS, Byun KS, Kim YJ, et al. Monotherapy with tenofovir disoproxil fumarate for adefovir-resistant vs. entecavir-resistant chronic hepatitis B: a 5-year clinical trial. J Hepatol 2019;71:35-44. 